J. Amer. Soc. Hort. SCI. 117(2):357-360. 1992.

\title{
A Low-pressure, Trunk-injection Method for Introducing Chemical Formulations into Olive Trees
}

\author{
C. Navarro \\ Departamento de Olivicultura, Centro de Investigación y Desarrolo Agrario, Apartado 240, 14071 \\ Córdoba, Spain
}

R. Fernández-Escobar and M. Benlloch

Departamento de Agronomía, Universidad de Códoba, Apartado 3048, 14080 Córdoba, Spain

Additional index words. Olea europaea, marker chemical, safranin, methylene blue, $\mathrm{RbCl}$, chemical distribution, transport

\begin{abstract}
A low-pressure injection method for introducing chemical formulations into trees is presented. The apparatus consists of a plastic injector and a tube providing a pressure of 60 to $80 \mathrm{kPa}$, which is below the injurious level for the xylem. The efficiency of the method was determined by injecting PTS, a marker of apoplastic flux dye solutions, and rubidium chloride into young trees, main scaffolds, or tree trunks. The depth of the hole drilled) and the number of injections necessary to distribute the solutions was also determined. The injected solutions moved mainly upward through the older rings of the xylem, suggesting that uptake is directly controlled by the transpiration rate. A single injection was enough to distribute solutions in scaffolds with a diameter of $8 \mathrm{~cm}$, but two injections were necessary for 17-cm-diameter trunks. According to the results, the injection method was effective in introducing chemicals into olive (Olea europaea L.) trees. The method is easy to use, safe and economical and does not involve special equipment. Chemical name used: trisodium, 3-hydroxi-5,8,10-pyrenetrisulfonate (PTS).
\end{abstract}

The need to maintain high rates of productivity in modern agriculture requires chemicals such as fertilizers, pesticides, or nontrophic organic products, such as growth regulators. These products are usually applied to the soil or by means of foliar application. Although these traditional application methods have great advantages, they are occasionally ineffective, often unacceptable in urban areas, and increase water and air pollution.

Trunk injection is an alternative application method for introducing chemical compounds into trees. Injections have many advantages: They 1) offer an efficient use of chemicals, 2) reduce environmental pollution, 3) are especially useful when soil and foliar applications are either ineffective or too difficult, and 4) can be used in rural and urban areas. Several injection methods, including trunk infusion (Nyland and Moller, 1973; Schreiber, 1969), bark banding (Backhaus et al., 1976; Koehler and Rosenthal, 1967), and pressurized trunk injection (Filer, 1973; Helburg et al., 1973; Reil and Beutel, 1976; Sterrett and Creager, 1977), have been developed since the beginning of the century. Trunk infusion consists of an apparatus in which the injector assemblies are connected to a nonpressurized container that is suspended from the tree above the injector assembly in such a way that the liquid is introduced into the tree by gravity. The process depends on transpirational water loss from the leaves to pull the solution from the container into the xylem. The disadvantages of this method are the high labor costs and failure to introduce the chemical into some species, as noted by Hock and Schreiber (1971) and by us in olive trees (unpublished). Bark banding consists of the impregnation of bark tissues with test solutions. Its utility is limited by movement of chemicals through bark tissues. Finally, pressurized injection forces solutions into the xylem, eliminating some of the problems encountered in the other methods. Among the various systems

Received for publication 5 Mar. 1990. The cost of publishing this paper was defrayed in part by the payment of page charges. Under postal regulations, this paper therefore must be hereby marked advertisement solely to indicate this fact. developed, the high-pressure, trunk-injection system described by Reil and Beutel (1976) is the most widely used for experimental purposes. Solutions can be injected at pressures of 0.7 to 1.4 MPa in a few minutes. Many fruit and landscape trees have been injected successfully with the use of this technique (Reil, 1979; Sachs et al., 1977); however, the commercial use of the system is limited because the equipment is not widely available and labor costs are high. In addition, injuries around the injection holes have been noted, especially when pressures were very high (Sachs et al., 1977).

This paper introduces a pressurized-injection method aimed at avoiding the problems described above. The method is a modification of that developed by Pinkas et al. (1973). The objective was to achieve a method that was easy to use, inexpensive, and one that did not require special equipment. Experiments were carried out with olive trees because of the reported ineffectiveness of foliar application methods (Leon and Bukovac, 1978).

\section{Materials and Methods}

The apparatus consists of two elements: a plastic injector for insertion into the tree trunk after a hole has been mechanically drilled and a latex tube containing the solution to be injected. Solution was placed into the tube under pressure by means of a syringe connected to the tube. The tube was closed at both ends by means of ties or clamps. After removing one of the ties or clamps, the pressurized tube provides a pressure of 60 to 80 $\mathrm{kPa}$ with the use of a 9-mm-diameter latex tube. Pressure was determined using a water-tight manometer.

The application procedure is as follows (Fig. 1): a) drilling a hole into the tree trunk, b) inserting the injector in the hole, and c) connecting the tube to the injector after removal of one of the ties or clamps that close the tube. Holes with a $6 \mathrm{~mm}$ diameter were drilled in tree trunks or scaffolds, with the exception of one experiment with young trees in which 3-mmdiameter holes were bored.

Distribution of injected solutes, effect of hole depth, and the 


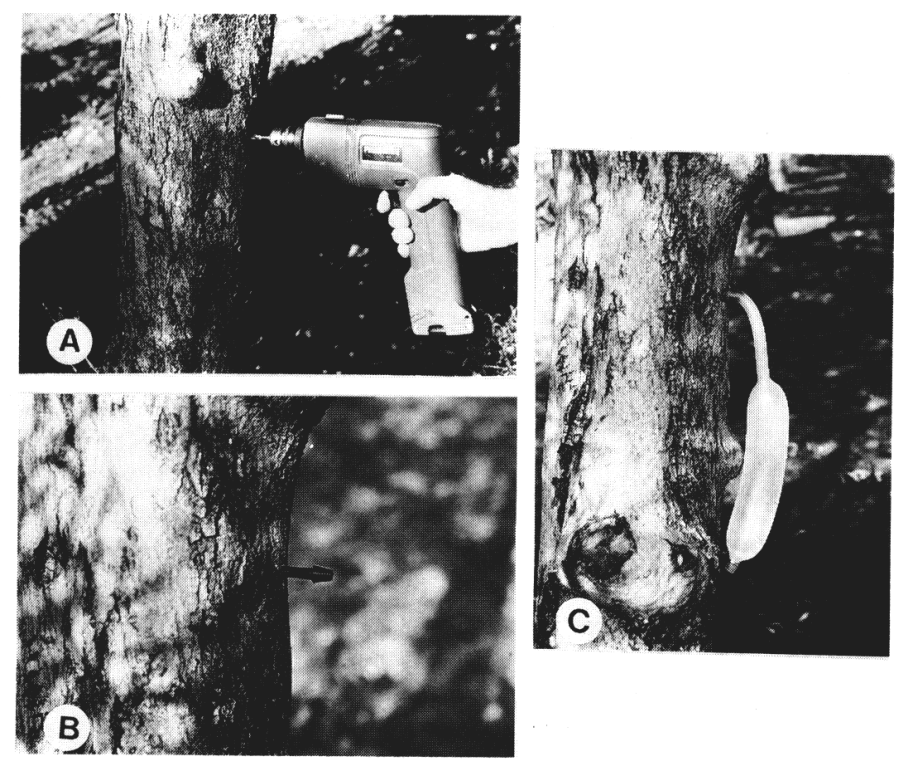

Fig. 1. Operational phases for the application of trunk injections. (A) Drilling of hole, $(\mathbf{B})$ insertion of the injector into the hole, and $(\mathbf{C})$ connection of the tube to the injector.

number of injections per tree were studied in 'Manzanillo' olive trees growing at the Experimental Farm of Alameda del Obispo at Córdoba. Three experiments were performed using trunks and scaffolds of different diameter.

Distribution of PTS in young trees (Expt. 1). 'Manzanillo' trees growing in 35-liter pots were selected for a trunk diameter of $\approx 2 \mathrm{~cm}$. Four plants were injected with $20 \mathrm{ml}$ of an aqueous solution $(0.01 \%, \mathrm{w} / \mathrm{v})$ of PTS, which is fluorescent, water soluble, nontoxic, and not adsorbed by the cell walls. It is used as a marker of apoplastic flux (Hanson et al., 1985). One hole, 1$\mathrm{cm}$ deep and $3 \mathrm{~mm}$ in diameter, was bored into each trunk. Ten leaves were excised $9 \mathrm{~h}$ after the solution had been completely taken up by the basal, middle, and apical sections of the aerial part of each tree. Twenty-four hours after uptake, root samples (3 $\mathrm{g}$ fresh weight) were taken from each injected plant. Leaf and root samples taken from untreated plants were used as controls. The samples were immersed in $30 \mathrm{ml}$ of 80 methanol : 20 water (v/v) for $12 \mathrm{~h}$. The liquid was analyzed on a PerkinElmer MPF-43A spectrofluorometer (Perkin-Elmer), using an excitation wavelength of $403 \mathrm{~nm}$ and an emission wavelength of $513 \mathrm{~nm}$ to determine the content of PTS (Hanson et al., 1985).

Distribution of dyes in shoot system (Expt. 2). Twelve-yearold 'Manzanillo' trees were used in a factorial experiment with hole depth and number of injections as factors. Treatments were carried out on the main scaffolds ( $\approx 8 \mathrm{~cm}$ in diameter). Holes were $2.5 \mathrm{~cm}$ or $4.5 \mathrm{~cm}$ deep drilled $140 \mathrm{~cm}$ from the scaffoldmain trunk junction. One or two injections were applied to each scaffold. When two injections were applied, holes were drilled at the same depth and spaced $90^{\circ}$ around the scaffold. Two histological dyes were injected to examine the movement of the solutions. All scaffolds were injected with $400 \mathrm{ml}$ of a red dye; i.e., $0.2 \%$ safranin solution. When two injections were applied to the same scaffold, the second injection was composed of 400 $\mathrm{ml} 0.4 \%$ methylene blue in water. The scaffolds were cut into sections $18 \mathrm{~h}$ after injection to locate the dye-containing regions. Cross sections were spaced $\approx 10 \mathrm{~cm}$. The movement of solutions was determined by measuring the angle of the arc of wood dyed in each cross section. Likewise, limbs and shoots of the main scaffold were cut and the percentage containing dye determined.

Distribution of rubidium in tree (Expt. 3). This experiment was designed to determine the number of injections necessary to distribute solutions in whole trees. 'Manzanillo' trees with a single trunk divided into three scaffolds were selected for a trunk diameter of $\approx 17 \mathrm{~cm}$. The design of the experiment was a randomized block consisting of three treatments with three singletree replications. The treatments were one, two, or three trunk injections of $50 \mathrm{mM}$ rubidium chloride $(\mathrm{RbCl})$. Holes were drilled $\approx 40 \mathrm{~cm}$ from the scaffold junction. Rubidium was used as a distribution marker in leaves because it is a rare element in nature, moves through the symplast, is easy to extract from leaf tissues, and has been widely used as a tracer for $\mathrm{K}^{+}$. The same volume of $\mathrm{RbCl}$ was injected in each treatment. Thus, the first treatment consisted of one injection of $600 \mathrm{ml}$, the second of two injections of $300 \mathrm{ml}$ each at $180^{\circ}$ intervals, and the third treatment of three injections of $200 \mathrm{ml}$ each spaced at $120^{\circ}$ intervals. Leaf samples were taken from the basal and apical section of each scaffold 1, 3, and 16 days after injection. Rubidium content was determined using the method developed by Benlloch et al. (1989). Leaves were immersed in $10 \%$ acetic acid for $12 \mathrm{~h}$, and then filtered and washed with boiling water. The content of $\mathrm{Rb}^{+}$was determined using a Perkin Elmer 603 atomic absorption spectrophotometer.

\section{Results}

Distribution of injected PTS in young trees. One injection in a hole $1 \mathrm{~cm}$ deep with a diameter of $3 \mathrm{~mm}$ was enough to distribute PTS in trees with 2-cm trunks. Evidence of PTS was found in leaves taken from the basal, middle, and apical sections of the aerial part of the trees and also in the roots (Fig. 2). The amount of PTS found in roots varied considerably; it was found in roots only in two of the four tree replicates. PTS was found in all leaf samples taken from the four replicates.

Distribution of dyes in shoot system. At the point of injection, the safranin dye appeared as an amorphous spot (Fig. 3A). Above that point, the dye formed concentric rings located in the inner part of the wood (Figs. $3 \mathrm{~B}$ and $\mathrm{C}$ ).

Hole depth and the number of injections per scaffold affect dye distribution in the shoot (Fig. 4). At the point of injection, two injections spaced $90^{\circ}$ around scaffolds with a diameter of

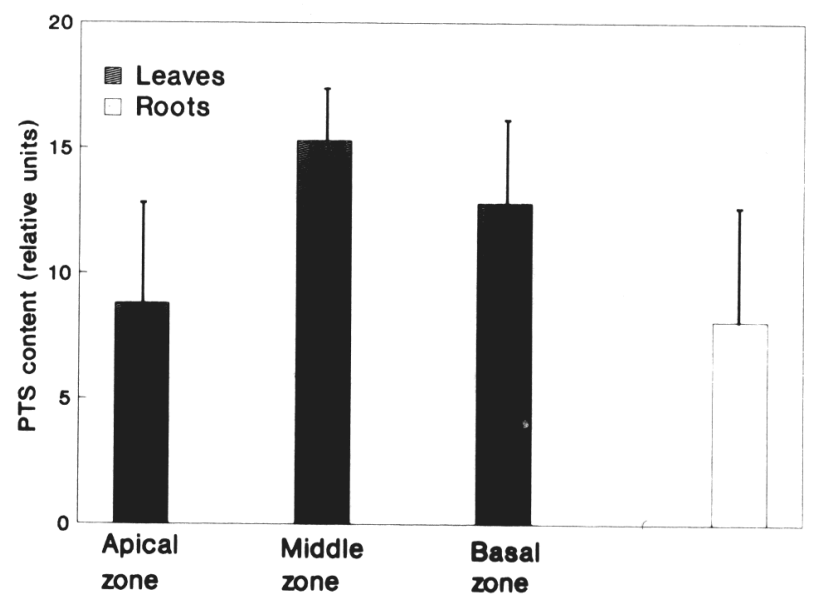

Fig. 2. Distribution of injected PTS in leaves and roots of trees with a diameter of $2 \mathrm{~cm}$. Twenty milliliters of an aqueous solution $(0.01 \%$ PTS) was injected into a 3-mm-diameter hole bored $1 \mathrm{~cm}$ deep in each tree. Bars represent the standard error. 

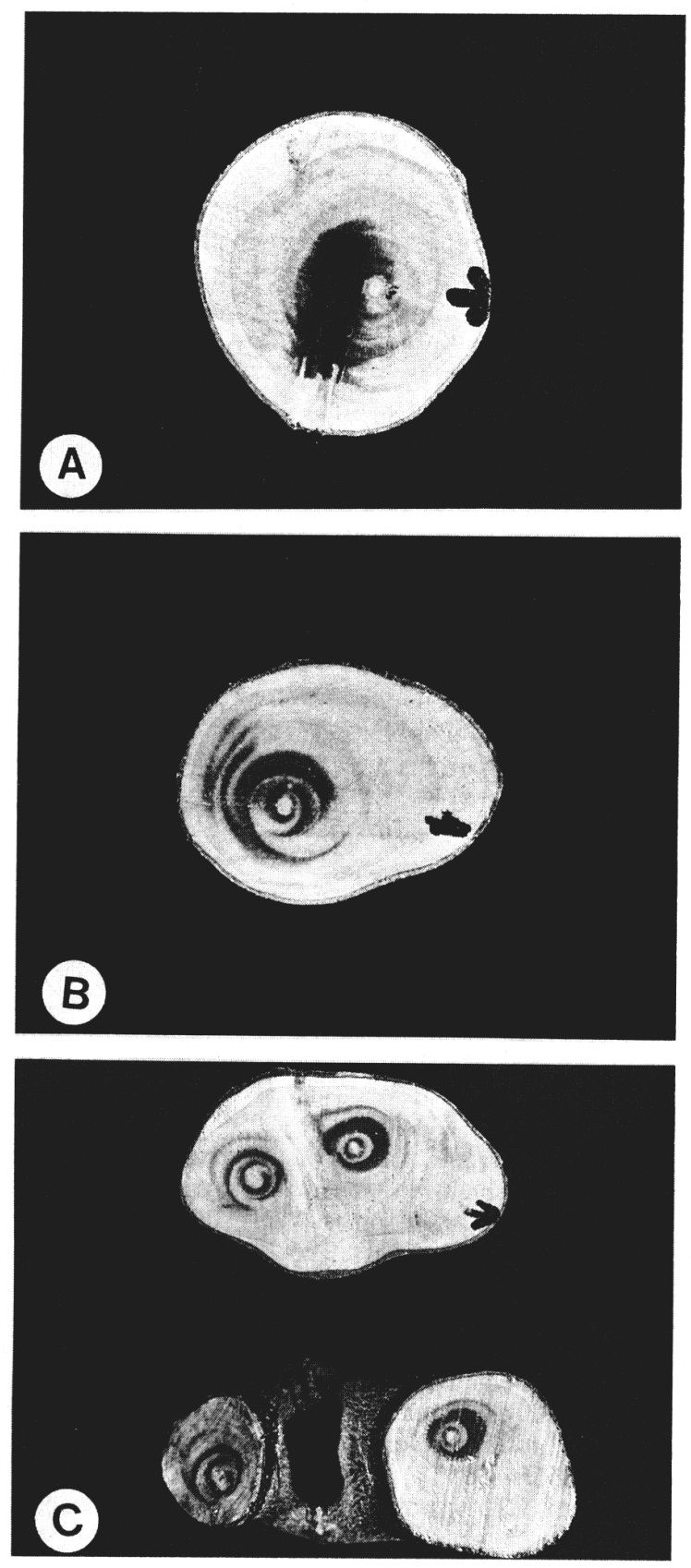

Fig. 3. Pattern of distribution of injected safranin dye into the shoot. (A) Spot at the point of injection, (B) $64 \mathrm{~cm}$ above the point of injection, (C) $112 \mathrm{~cm}$ above the point of injection after branching.

$8 \mathrm{~cm}$ spread in an $\operatorname{arc} 348^{\circ}$ to $356^{\circ}$ wide, whereas one injection spread dye in an arc $249^{\circ}$ to $298^{\circ}$ wide. No significant differences were found with hole depth, although in the case of one injection, deeper holes covered wider arcs. Dyed rings that covered in an $\operatorname{arc} 360^{\circ}$ wide were found $10 \mathrm{~cm}$ above the point of injection when two injections were applied, $20 \mathrm{~cm}$ above that point with one injection $4.5 \mathrm{~cm}$ deep, and $40 \mathrm{~cm}$ above the injection with one injection $2.5 \mathrm{~cm}$ deep.

As distance below the injection site increased, dyes spread in narrower arcs (Fig. 4) until the spots disappeared. The greatest distance obtained by dyes below the point of injection was 137 $\mathrm{cm}$, and the average was $81 \mathrm{~cm}$.

Neither the number of injections nor the hole depth affected dye distribution in limbs and shoots directly inserted in the scaf-

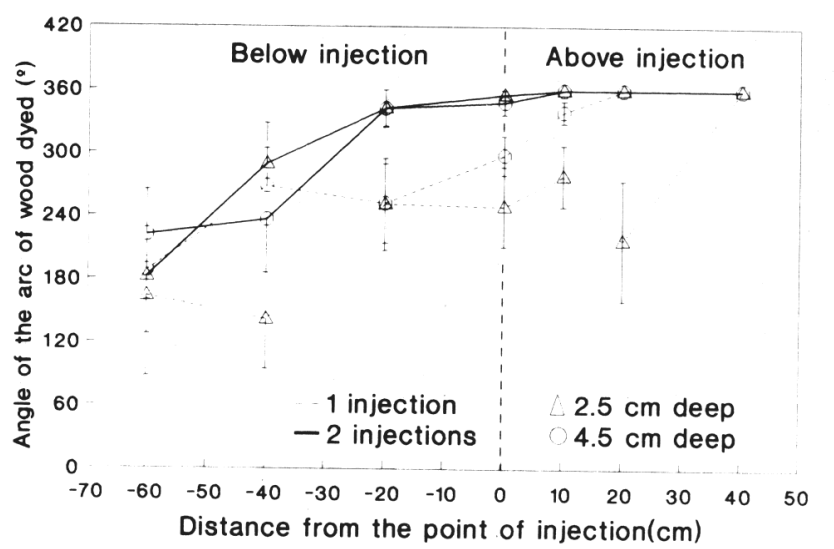

Fig. 4. Influence of number of injections and depth of injection hole on distribution of dyes in scaffolds with a diameter of $8 \mathrm{~cm}$.

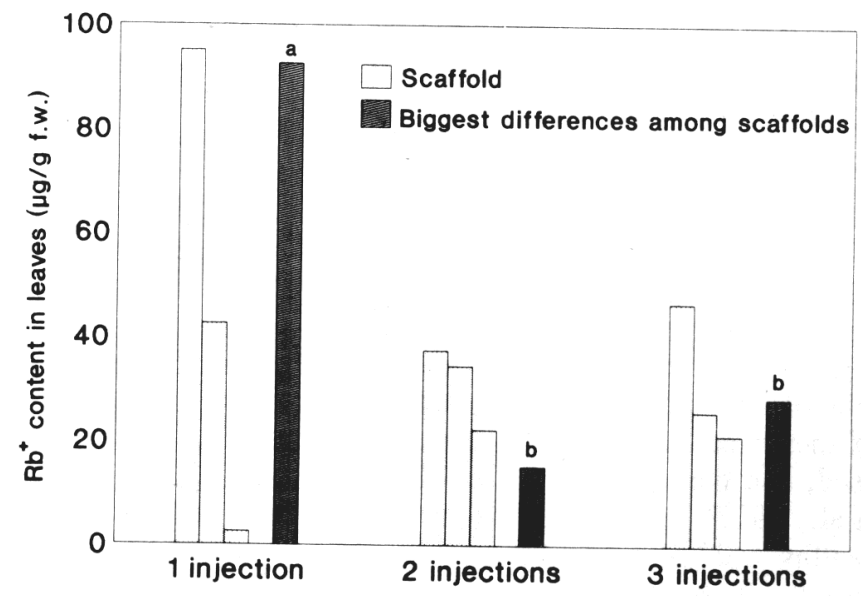

Fig. 5. Influence of the number of injections into 17-cm-diameter trunks on the distribution of injected $\mathrm{Rb}^{+}$in leaves. Trees with a single trunk dividing into three scaffolds were selected for the experiment. Mean separation was accomplished by Duncan's multiple range test $(P=0.05)$.

folds. The proportions of secondary limbs dyed with one injection were $82 \%$ and $91 \%$ above and $56 \%$ and $57 \%$ below the injection; with two injections, the respective values were $90 \%$ and $98 \%$ and $78 \%$ and $77 \%$ for depths of 2.5 and $4.5 \mathrm{~cm}$, respectively, in each pair. This means that one injection applied in a hole at least $2.5 \mathrm{~cm}$ deep was enough to distribute the solutions in scaffolds with diameters of $8 \mathrm{~cm}$. However, a significant correlation $(r=0.8)$ was found between the dyed arc at the point of injection and the percentage of limbs and shoots dyed, indicating that the wider the arc covered by solutions at the injection point, the better the distribution in the tree.

Distribution of $R b^{+}$in tree. Two injections were necessary to distribute trunk-injected $\mathrm{Rb}^{+}$into the three scaffolds of trees with a trunk diameter of $17 \mathrm{~cm}$ (Fig. 5). Three injections per trunk did not improve distribution and one injection was insufficient to distribute solution into the three scaffolds. With only one injection, $\mathrm{Rb}^{+}$was found mainly in the leaves of one scaffold, which usually was the one located near the point of injection. Only traces of $\mathrm{Rb}^{+}$were found in leaves of one of the three scaffolds of each tree.

Higher contents of $\mathrm{Rb}^{+}$were found in leaves taken from the basal section of the tree than in those taken from the upper part (Fig. 6). Although $\mathrm{Rb}^{+}$may be redistributed in the tree after uptake, the differences found $24 \mathrm{~h}$ after injection suggested a 


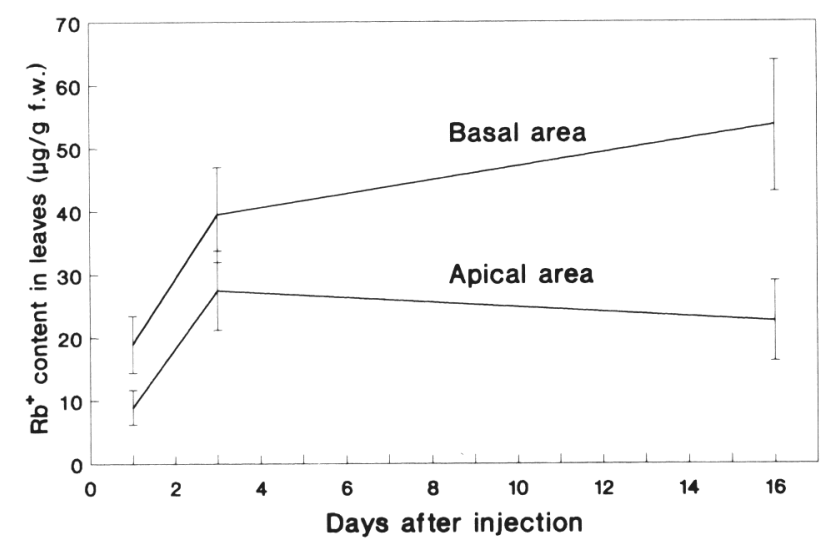

Fig. 6. Change of $\mathrm{Rb}^{+}$content in leaves taken from the basal and the apical areas of the scaffolds. Each point represents the mean of 27 values. Vertical bars are standard errors.

tendency to accumulate in the basal leaves before retranslocation occurs.

\section{Discussion}

Trunk injection of aqueous solutions is a recently developed method for applying chemical compounds to trees. Consequently, only a limited knowledge is available on the use of injections in horticultural practice. Many factors may affect uptake of injected solutions, including those related to the nature of the plant material, environmental conditions, the chemical used, and the injection system (Filer, 1973; Reil, 1979; Sachs et al., 1977). In our experiments with olives trees, we selected healthy trees and applied the injections during the vegetative period, on sunny days, and late in the morning to minimize variability.

The low-pressure system described for injecting chemicals into trees is an effective technique for the distribution of solutions to the aerial part of the tree (Figs. 2 and 4). The apparatus facilitated uptake of solutions at pressures below those that would injure the xylem (Kramer and Kozlowski, 1979). Solutions moved up and down the trunk from the injection point due to the pressure provided by the latex tube. Subsequent distribution was mainly upward via the transpiration stream. This pattern was verified by the presence of 1) PTS, which moved through the apoplast (Hanson et al., 1985) into apical leaves (Fig. 2), and 2) injected dyes, which moved upward through the inner rings of the olive xylem, the path of lowest resistance (Fig. 3).

The number of injections necessary to uniformly distribute chemicals throughout the tree depended on tree size. These results are in agreement with those reported with other injection methods (Nyland and Moller, 1973; Reil, 1979). However, the depth of the hole drilled may play an important role in the uptake and distribution of the injected solution and may affect the number of injections required. Sachs et al. (1977), working with a high-pressure injection system, found an increase in the injection rate by drilling deeper holes. In our experiments, uptake rate varied between 10 and $95 \mathrm{~min}$, with the exception of the experiment with PTS in young trees in which uptake lasted more than $2 \mathrm{~h}$. The uptake of injected solutions seems to be affected by both hole depth and the rate of transpiration.

Hole depth also affects the distribution of chemicals throughout the tree. When safranin and methylene blue solutions were injected, a high correlation between the dyed arcs of wood at the point of injection and the number of secondary limbs dyed was observed. Deeper holes allowed solutions to reach the inner regions of stem or branch wood and facilitated a wider arc of coverage (Fig. 4). Considering that the deepest hole drilled was $4.5 \mathrm{~cm}$, this may explain why one injection was enough to distribute solutions in scaffolds with diameters of $8 \mathrm{~cm}$, whereas two injections were necessary to distribute solutions in $17-\mathrm{cm}$ trunks. Therefore, our data support the hypothesis that if it is possible to inject solutions directly in the pith, one injection may be enough to distribute solutions in olive trunks or scaffolds regardless of diameter. This supposition was not verified in our research because the drill bit was too short to access pith regions.

The injection method described is 1) effective in applying chemical formulations, 2) easy to use, 3) safe and economical, and 4) does not require special equipment. The volume of solution to be applied may vary depending on the length of the tube to be filled. Although, in the present study, we injected 20, 200, 300, 400, and $600 \mathrm{ml}$, we selected $250 \mathrm{ml}$ for general purposes in later experiments. Moreover, these experiments allow us to recommend that when trees with a single, short trunk dividing into a few scaffolds are encountered, the injection should be placed under the scaffolds to ensure a good distribution of the chemical throughout the entire tree.

\section{Literature Cited}

Backhaus, R.A., H. Hield, and R.M. Sachs. 1976. Tree growth inhibition by bark applications of morphactins. HortScience 11:578580 .

Benlloch, M., I. Moreno, and A. Rodriguez-Navarro. 1989. Two modes of rubidium uptake in sunflower plants. Plant Physiol. 90:939-942.

Filer, T.H. 1973. Pressure apparatus for injecting chemicals into trees. Plant Dis. Rptr. 57:338-341.

Hanson, P.J., E.I. Sucoff, and A.H. Markhart. 1985. Quantifying apoplastic flux through red pine root systems using trisodium, 3hydroxy-5,8,10-pyrenetrisulfonate. Plant Physiol. 77:21-24.

Helburg, L.B., M.E. Schomaker, and R.A. Morrow. 1973. A new trunk injection technique for systemic chemicals. Plant Dis. Rptr. 57:513-514.

Hock, W.K. and L.R. Schreiber. 1971. Evaluation of benomyl for the control of Dutch elm disease. Plant Dis. Rptr. 55:58-60.

Koehler, C.S. and S.S. Rosenthal. 1967. Bark vs. foliage applications of insecticides for control of Psylla uncatoides on Acacia. J. Econ. Entomol. 60:1554-1558.

Kramer, P.J. and T.T. Kozlowski. 1979. Physiology of woody plants. Academic, New York.

Leon, J.M. and M.J. Bukovac. 1978. Cuticle development and surface morphology of olive leaves with reference to penetration of foliarapplied chemicals. J. Amer. Soc. Hort. Sci. 103:465-472.

Nyland, G. and W.J. Moller. 1973. Control of pear decline with a tetracycline. Plant Dis. Rptr. 57:634-637.

Pinkas, Y., E. Shabi, Z. Solel, and A. Cohen. 1973. Infiltration and translocation of thiabendazole in apple trees by means of a pressure injection technique. Phytopathology 63:1166-1168.

Reil, W.O. and J.A. Beutel. 1976. A pressure machine for injecting trees. Calif. Agr. 30:4-5.

Reil, W.O. 1979. Pressure-injecting chemicals into trees. Calif. Agr. 33:16-19.

Sach, R.M., G. Nyland, W.P. Hackett, J. Coffelt, J. Debie, and G. Giannini. 1977. Pressurized injection of aqueous solutions into tree trunks. Scientia Hort. 6:297-310.

Schreiber, L.R. 1969. A method for the injection of chemicals into trees. Plant Dis. Rptr. 53:764-765.

Sterrett, J.P. and R.A. Creager. 1977. A miniature pressure injector for deciduous woody seedlings and branches. HortScience 12:156158. 